\title{
Monitoring of Trace Amounts of Chromium in Ordinary Portland Cement Using X-Ray Absorption Fine Structure Analysis
}

\author{
Isao TSUYUMOTO* and Hiroshi UCHIKAWA \\ Division of Environmental Engineering, Kanazawa Institute of Technology, \\ 7-1, Ohgigaoka, Nonoichi-machi, Ishikawa-gun, Ishikawa 921-8501
}

\author{
X 線吸収微細構造による標準ポルトランドセメント中の微量クロムの分析 \\ 露本伊佐男* . 内川 浩 \\ 金沢工業大学工学部環境系, 921-8501 石川県石川郡野々市町扇が丘 7-1
}

\begin{abstract}
Trace amounts of chromium ( $\sim 6.4$ mass ppm of $\mathrm{Cr}(\mathrm{VI})$ and 58.4 mass ppm of total $\mathrm{Cr}$ ) in ordinary Portland cement was monitored in hydration process using XAFS (X-ray absorption fine structure). Our XAFS data indicated the hexavalent chromium $(\mathrm{Cr}(\mathrm{VI}))$ in cement was decreased as the hydration of cement proceeds. Little divalent iron contained in cement was assumed to act as a reducing agent, and a technique to prevent the elution of chromium was proposed in this connection.
\end{abstract}

[Received February 24, 2003; Accepted May 26, 2003]

Key-words : X-ray absorption fine structure, X-ray absorption near edge structure, Chromium, Cement

\section{Introduction}

An understanding of chemical states of toxic heavy metals in the environment is essential to assess potential hazards, because the mobility, bioavailability, and treatability of the heavy metals are affected by the solubility of the solid-phase metal species and aqueous-phase speciation. ${ }^{1)}$ Cement has been widely employed to stabilize and solidify waste materials containing the heavy metals, and the longterm leachability of the cement-stabilized residues is the important factor associated with landfilling. Zielgler et al. used $\mathrm{X}$-ray absorption fine structure (XAFS) spectroscopy to elucidate the binding mechanism of $\mathrm{Zn}$ (II) to calcium silicate hydrate $(\mathrm{C}-\mathrm{S}-\mathrm{H})$ and confirmed the presence of $\mathrm{Si}-\mathrm{O}-\mathrm{Zn}$ bonds. ${ }^{2)}$ Most of the early reports, however, focused on the stabilization of the waste materials with cement and investigated the speciation of the heavy metals at rather high concentrations.

On the other hand, elution of hexavalent chromium from cement itself has become an environmental problem as well as from the cement-stabilized waste residues. This tendency is remarkable when cement is used as soil stabilizer. The chromium is probably derived from the raw materials such as iron slag and the refractory bricks, and it is treated in the clinkering process over $1400^{\circ} \mathrm{C}$, at which chemical reactions through molten phases occur. Thus the concentration and chemical state are different from the case with the cementstabilized waste residues. In recent years, techniques to manufacture cements from the incineration ash of urban refuses and sewage sludge have been developed.3),4) We should pay much attention in using such waste materials because trace heavy metals incorporated in cement may bring about a hazardous risk. Thus it is essential to evaluate the behavior of trace heavy metals in cement by analyzing their chemical states during hydration in order to assess a potential environmental risk.

In this study, we focused on the XAFS analysis of the behavior of trace chromium in ordinary Portland cement. In speciation of chromium, it is highly desirable to quantify hexavalent chromium $(\mathrm{Cr}(\mathrm{VI}))$ and trivalent chromium (Cr (III) ) severally, because the hexavalent chromium is toxic and soluble in water while the trivalent chromium is nontoxic and mostly insoluble in water. There are some reports on speciation of chromium using X-ray absorption near-edge structure (XANES) spectroscopy.5)-7) Shaffer et al. suggested that an XANES measurement can be used for both the quantitative analysis and speciation of soil samples contaminated with greater than 10 mass ppm chromium. ${ }^{5)}$ We investigated here the applicability of fluorescence XAFS analysis as an automated chemical analysis of chromium in cement matrix at the 1 mass ppm level, and monitored a redox reaction between $\mathrm{Cr}(\mathrm{VI})$ and $\mathrm{Cr}(\mathrm{III})$ during cement hydration.

\section{Experimental}

\subsection{Samples}

Standard sample of ordinary Portland cement sample was supplied by the Japan Cement Association. Hydrated cement samples were prepared by mixing with water in a sample bottle, and the cement paste had a water/cement ratio of 0.5 . The sample bottles were sealed and cured in an incubator at $20^{\circ} \mathrm{C}$ for 14,35 and $76 \mathrm{~d}$. Reference samples containing $20 \mathrm{mg}$ of $\mathrm{Cr}$ were prepared using $\mathrm{Na}_{2} \mathrm{CrO}_{4} \cdot 4 \mathrm{H}_{2} \mathrm{O}, \mathrm{Cr}_{2} \mathrm{O}_{3}$, $\mathrm{CrO}_{3}$, and $\mathrm{Cr}(\mathrm{OH})_{3} \cdot n \mathrm{H}_{2} \mathrm{O}$, respectively. Each reference sample was mixed with $100 \mathrm{mg}$ of $\mathrm{BN}$ (boron nitride) and was pressed into pellet of $13 \mathrm{~mm} \phi$ at $80 \mathrm{kN}$ for $10 \mathrm{~min}$.

The concentrations of total chromium and of hexavalent chromium in the unhydrated cement powder were determined by the conventional wet analysis. The concentration of the hexavalent chromium was determined at 6.4 mass ppm using the diphenylcarbazide absorption spectrophotometry after water extraction, and that of the total chromium was determined at 58.4 mass ppm using the atomic absorption spectrometry. This chromium is intrinsic to cement materials and supposed to be derived from the natural raw materials and the refractory bricks.

2.2 X-ray absorption fine structure (XAFS) spectroscopy

Data collection

XAFS spectra were recorded at beamline BL38B01 of SPring-8 (Japan Synchrotron Radiation Research Institute, JASRI; West Harima, Hyogo). An Si-(111) double-crystal monochromator was used, and higher harmonics were eliminated with Rh-coated mirrors. Beam energy was calibrated by assigning the first inflection on the L3 absorption edge of 
a $\mathrm{Pb}$ metal foil to an energy of $13.035 \mathrm{keV}$. The spectra of unhydrated and hydrated cement samples were collected in fluorescence mode using a Ge 19-element SSD (GL0110S, Canberra Industries Inc.). The spectra of the reference samples were collected in transmission mode using two ion chambers for $I_{0}$ and $I$, both of which were filled with $\mathrm{N}_{2}$. The scan step was $0.3-0.4 \mathrm{eV}$. All scans were collected in triplicate and averaged to improve the signal-to-noise ratio. The samples were oriented at $45^{\circ}$ to the incident beam, and the measurements were conducted at room temperature to avoid transformation of cement materials. Twenty-four sheets of $25 \mu$ m-thick Kapton polyimide film were stacked (total thickness of $600 \mu \mathrm{m}$ ) and placed in front of the fluorescence detector to reduce the amount of background from such as fluorescence from Ca, Ti, V, Fe, Mn, Thomson scattering, Compton scattering.

Data analysis

Data reduction was carried out using WinXAS 2.2.8) The background offset of the chromium XANES spectrum was removed by subtracting a line fit to the pre-edge data. The step heights were normalized to unity using difference of the average intensities of $5.96 \mathrm{keV}-5.98 \mathrm{keV}$ and $6.4 \mathrm{keV}-6.5$ $\mathrm{keV}$. As shown in Fig. 1, samples containing tetrahedralcoordinated chromium $(\mathrm{Cr}(\mathrm{VI}))$ exhibit the distinct absorption peak prior to the main $\mathrm{Cr} \mathrm{K}$ absorption edge (indicated by a solid arrow). This pre-edge absorption resonance is due to electronic transitions from the 1 s core state to the $3 \mathrm{~d}$ molecular orbital state, and sometimes characteristic to transition metals with empty d orbitals. These pre-edge features are also observed for $\mathrm{Ti}(\mathrm{IV}), \mathrm{V}(\mathrm{V})$, and $\mathrm{Mn}(\mathrm{VII}) .^{7)}$ We used the intensity of the $\mathrm{Cr} \mathrm{K}$ pre-edge peak for quantitative analysis of the hexavalent chromium $(\mathrm{Cr}(\mathrm{VI}))$ in cement matrix. We estimated the baseline by an interpolation and subtracted the baseline from the peak. The peak was fitted with a sum of a Gaussian function and a Lorentzian function, and the area of the fitted functions was used for quantitative analysis. For comparison, we also determined the peak area by numerical integration after subtracting the

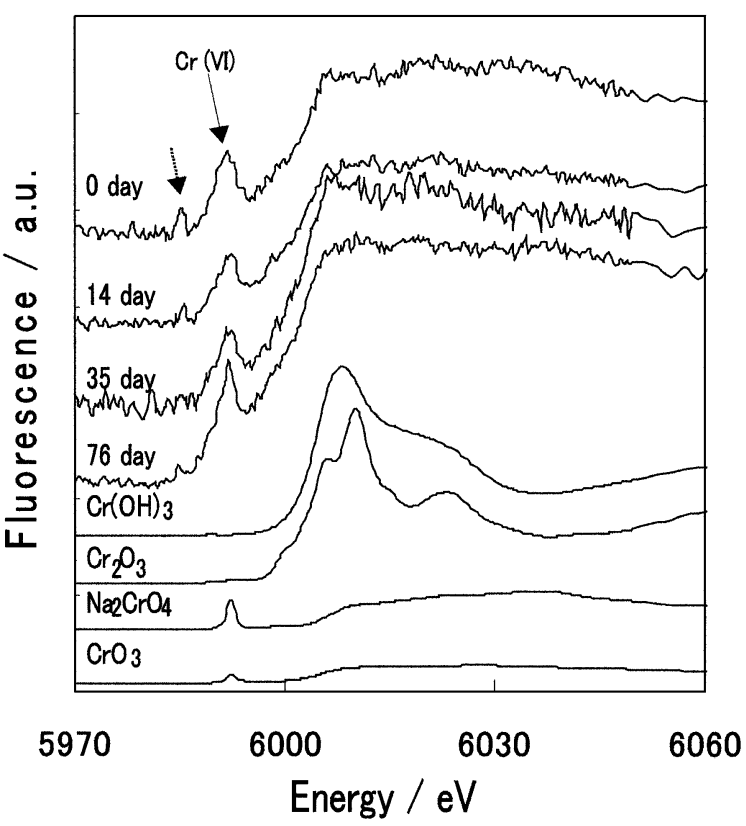

Fig. 1. XANES spectra for ordinary Portland cement at the age of 0, 14, 35 and $76 \mathrm{~d}$, along with $\mathrm{Cr}(\mathrm{OH})_{3}, \mathrm{Cr}_{2} \mathrm{O}_{3}, \mathrm{Na}_{2} \mathrm{CrO}_{4}$ and $\mathrm{CrO}_{3}$ for reference. Counts of $\mathrm{Cr} \mathrm{K} \alpha$ fluorescence are normalized, and the spectra are vertically deviated for clarity. baseline.

\section{Results and discussion}

A peak due to hexavalent chromium was observed at 5993 $\mathrm{eV}$ in the pre-edge region of the spectrum in Fig. 1 (indicated by a solid arrow). The peak of the unhydrated cement (at the age of $0 \mathrm{~d}$ ) is due to 6.4 mass ppm of hexavalent chromium. The detection limit of the hexavalent chromium in the cement matrix using this measurement system was approximately estimated at 1.6 mass $\mathrm{ppm}$ from the singnal-to-noise ratio of the pre-edge region. X-ray fluorescence from abundant calcium in the cement matrix $(\mathrm{CaO}: 64.3 \%)$ somewhat disturbs the measurements compared to the soil samples. ${ }^{5)}$ In addition, a small peak was also observed around $5985 \mathrm{eV}$ for the samples at the age of 0 and $14 \mathrm{~d}$ (indicated by a dotted arrow). Although these peaks have not been assigned so far, our results suggest that they are due to chemical species which are contained in unhydrated cement and vanish with hydration.

The area of the pre-edge peak around $5993 \mathrm{eV}$ was estimated with two different procedures and plotted as a function of material age in Fig. 2. We found that the peak area due to the hexavalent chromium was decreased monotonously with the material age, i.e., with the cement hydration. This indicates that the trace hexavalent chromium intrinsically contained in cement is gradually reduced to trivalent chromium during the hydration process and thus its toxicity and solubility decreases with elapsed time. The curve in Fig. 2 appears to be similar to that of the amount of hydration product of cement, which almost saturates over $\left.30 \mathrm{~d} .{ }^{9}\right)$ This suggests that the reduction of the hexavalent chromium to the trivalent chromium is involved in the hydration reaction.

The reducing mechanism can be explained based on former reports. Peterson el al. performed XAFS spectroscopy of Cr-contaminated soils and demonstrated that $\mathrm{Cr}(\mathrm{VI})$ is reduced to $\mathrm{Cr}$ (III) by naturally occurring magnetite (Fe(II) $\mathrm{Fe}(\mathrm{III})_{2} \mathrm{O}_{4}$ ), whereas $\mathrm{Cr}(\mathrm{VI})$ is not reduced on non $\mathrm{Fe}(\mathrm{II})$ bearing minerals. ${ }^{10)}$ In the cement industry it is well-known that little part of the iron oxide actually exists as divalent state, though much effort has been made to oxidize iron completely to trivalent state (Fe(III)) in cement burning process. Thus we consider that little divalent iron in the cement acts as a reducing agent which reduces the hexavalent

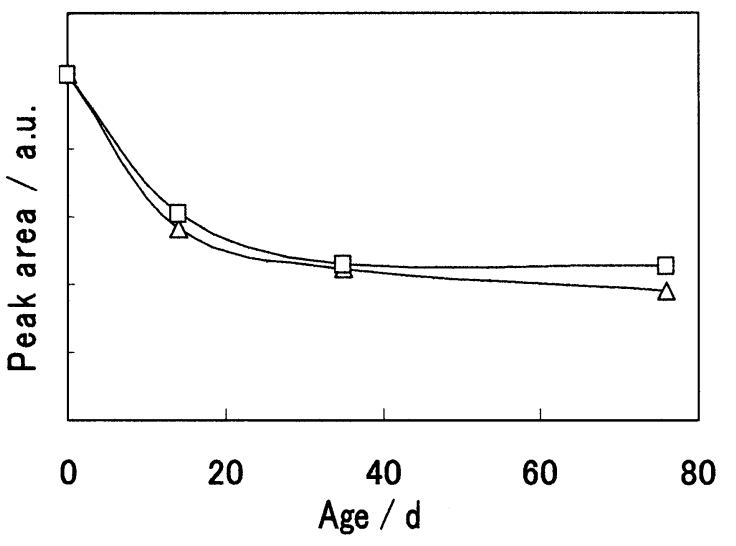

Fig. 2. Normalized area of the hexavalent pre-edge peak versus material age after mixing with water of the ordinary Portland cement. Peak area estimated by numerical integration is depicted by $\square$, and that estimated by a fit with the sum of a Gaussian and a Lorentzian functions is depicted by $\triangle$. The curves are guide-foreye. 
chromium to the trivalent chromium. The hexavalent chromium $\left(\mathrm{CrO}_{4}^{2-}\right)$ contained in cement minerals is dissolved in aqueous solution in micropores of cement matrix, and it is reduced by divalent iron ion. Exchange of electrons in the redox process is likely to occur in aqueous phase in micropores because it takes place in hydration process.

On the basis of these XANES results we demonstrated the decrease of the ratio of $\mathrm{Cr}(\mathrm{VI})$ to total $\mathrm{Cr}$ during hydration in cement matrix. It is important to note that the valence state of the chromium is easily affected by a redox agent since the content of the chromium is extremely low. In other words, in order to prevent elution of toxic chromium it is suitable to bear Fe(II) in cement. This idea is analogous to the sacrificial anode for cathodic protection in corrosion prevention technology. This information provides helpful direction in the cement production from waste materials as well as in the design of stabilizer of waste materials. In addition, monitoring of trace amounts of hazardous heavy metals by an automated routine analysis will be necessary in future for the quality control in the cement industry and for the hazard assessment of the landfilling of industrial wastes. We believe XAFS analysis will be a powerful tool for such purposes.

\section{Conclusions}

We applied the XAFS analysis to monitor trace amounts of chromium in ordinary Portland cement and observed a pre-edge peak due to 6.4 mass ppm of hexavalent chromium. Our XAFS data indicated the hexavalent chromium in cement was decreased as the hydration of cement proceeded. Little divalent iron contained in cement is assumed to reduce the chromium, and this suggests that the elution of the chromium can be prevented by bearing $\mathrm{Fe}$ (II) in cement matrix.

Acknowledgement We thank Drs. Hajime Tanida and Tomoya Uruga (Japan Synchrotron Radiation Research Institute, SPring-8) in performing the X-ray absorption fine structure experiments. The X-ray absorption fine structure experiments have been performed under the approval of the SPring-8 Program Review Committee (Nos. 2001B0227-NX-np, 2002A0074-CX-np). Standard sample of ordinary Portland cement was supplied by the Japan Cement Association. This work was partially supported by a grant from the Japan Cement Association.

\section{References}

1) Hesterberg, D., Sayers, D. E., Zhou, W., Plummer, G. M. and Robarge, W. P., Environ. Sci. Technol., Vol. 32, pp. 2840-2846 (1997).

2) Ziegler, F., Scheidegger, A. M., Johnson, C. A., Dähn, R. and Wieland, E., Environ. Sci. Technol., Vol. 35, pp. 1550-1555 (2001).

3) Uchikawa, H. and Obana, H., World Cement, Vol. 26, pp. 33-36 (1995).

4) Uchikawa, H. and Hanehara, S., "Waste Materials and Industrial By-Product in Concrete Manufacturing," Noyes Publications, Park Ridge (1997).

5) Shaffer, R. E., Cross, J. O., Rose-Pehrsson, S. L. and Elam, W. T., Anal. Chim. Acta, Vol. 442, pp. 295-304 (2001).

6) Lee, J. F., Bajt, S., Clark, S. B., Lamble, G. M., Langton, C. A. and Oji, L. Physica B, Vol. 208/209, pp. 577-578 (1995).

7) Bajt, S., Clark, S. B., Sutton, S. R., Rivers, M. L. and Smith, J. V., Anal. Chem., Vol. 65, pp. 1800-1804 (1993).

8) Ressler, T., J. Synch. Rad., Vol. 5, pp. 118-122 (1998).

9) Mehta, P. K. and Monterio, P. J. M., "Concrete-Microstructure, Properties, and Materials, Second Edition," McGrawHill Companies, New York (1998) pp. 198-201.

10) Peterson, M. L., Brown, G. E., Jr. and Parks, G. A., J. Phys. $I V$, Vol. 7, pp. 781-783 (1997). 